\title{
SOIL BIOTECHNOLOGY TO TREAT NAZAFGARH DRAIN WATER BEFORE DISPOSAL INTO RIVER YAMUNA
}

\author{
Rupali Gupta, Shivam Aggarwal, Vaibhaw Vishal and Vaishali Sahu \\ Department of Civil \& Environmental Engineering, The NorthCap University, Gurgaon, \\ Haryana,India
}

\begin{abstract}
The potential risks associated with the use of recycled water have become a matter of concern for many organisations which are recycling water. Out of the many reasons, the major ones are that they are not able to maintain the efficiency of the treatment plant and to meet the high energy demand of these plants. These problems have led to restricted usage of treatment plants by the industries hence they allow the waste water to bypass directly into the natural water bodies without any treatment. This work has taken into consideration the issue of river Yamuna in Delhi, which is one of the most polluted rivers of the world. It has been identified that Nazafgarh drain located in west Delhi has got a major contribution in the polluting Yamuna. The need of the hour is to find an innovative solution to resolve the problem of water recycling and offer a platform to the industries where the burden of treating their factory effluents is taken care of. This paper proposes a 1 MLD water treatment plant based on Soil Biotechnology which can efficiently treat the Nazafgarh drain water and make it fit for disposal into Yamuna. SBT is an eco-friendly and sustainable technology developed at IIT Bombay which provides all levels of treatment in a single evergreen set up open to atmosphere which is odorless, cheap, simple to operate, easy to maintain and could be set up within the area of habilitation.
\end{abstract}

\section{KEYWORDS}

ASP, BOD, COD, SBT, Yamuna

\section{INTRODUCTION}

Since the existence of our mother earth, it has got a limited amount of resources, may it be land, water or air. In other words, we can say that nothing is being created nor destroyed but converted from one form to another as stated in the law of conservation of energy. Hence if we consider the case of air, the air that we are breathing today is the same which we exhaled yesterday. Similar is the case with water, but the difference is that air is recycled naturally, whereas water has got its limits for natural recycling so it needs to be treated by other means. If water is heavily polluted then the natural system fails which is substituted by manmade technologies.

Earth has got only $2.5 \%$ of fresh water out of which only $0.01 \%$ can be accessed by humans as the rest is frozen as glaciers and ice bergs. We don't realise that fact that we are polluting even this available small percentage of this precious resource at an alarming rate. 
Civil Engineering and Urban Planning: An International Journal(CiVEJ) Vol.2,No.4, September 2015

The rivers are the main sources of water for every city. For example, US is nurtured by river Thames, Egypt by river Nile and of all India is blessed to have 10 major river systems namely Indus, Ganga, Yamuna, Brahmaputra, Tapi, Godavari, Narmada, Krishna, Kaveri and Mahanadi. Out of it, a major issue of concern is with river Yamuna which has a stretch of $1367 \mathrm{~km}$ before it merges with river Ganga in Allahabad. The river extends in the states of Uttar Pradesh, Himachal Pradesh, Haryana, Rajasthan, Madhya Pradesh and the entire union territory of Delhi. Only 2\% of Yamuna flows through Delhi but on the contrary the capital contributes its $70 \%$ pollution load. Although the rivers have a mechanism to self-purify but the rate at which a river can purify is much less than the rate at which it being polluted and the way it is being polluted is also a matter of concern.

Hence water recycling has now become a compulsory vertical to run a civilization efficiently and to meet the unbound needs of the growing population. To serve this purpose, many conventional technologies like ASP (Activated Sludge Process), UASB (Upflow Anaerobic Sludge Blanket process), Physco- Chemical process etc. are in practice since last many years.

The question arises here, that if we have methods to treat waste water then why we are polluting the precious water resources by disposing raw sewerage and untreated industrial effluent waste.

The answer to this is that the construction, operation and maintenance of the plants based on above mentioned conventional technologies and many other mechanical methods is quite difficult to be undertaken and also to sustain. Many organisations run short of space and hence they are not able to install a water treatment plant. Out of the few which have installed any, are facing difficulties to operate it and hence choose an option to bypass the raw effluent directly to nearby rivers. In fact, much government owned treatment plants have failed to maintain the effluent water quality and many have even shutdown.

The reason for such failures can be:

- High energy requirements

- Need of skilled labour to operate the plants

- High operational cost

- Heavy maintenance for the moving mechanical parts

- Sludge handling processes

- Unhygienic and false odour surroundings

- Large area requirements

A solution to all these problems is Soil Biotechnology, discussed in the next section.

\section{SOIL BIOTECHNOGY}

SBT is an indigenous technology developed by Prof HS Shankar, Department of Chemical Engineering, Indian Institute of Technology. It is covered under the US and Indian Patent. SBT has been awarded the Siemens award and also selected as one of the four, India's most Innovative technologies by Ministry of External Affairs, GOI. The technology exists in the domain of MCGM, KDMC etc.

There are several plants existing in India based on SBT which includes:

- 3MLD Sewage Purification in Corporation Of Bombay, Maharashtra

- 120 KLD Plant at Airport Udaipur, Rajasthan under Airport Authority of India

- 140 KLD plant at Lucknow Airport, Uttar Pradesh

- $10 \mathrm{KLD}$ plant at a chemical factory in Chandigarh

SBT completely recycles the water as shown in figure 1. 


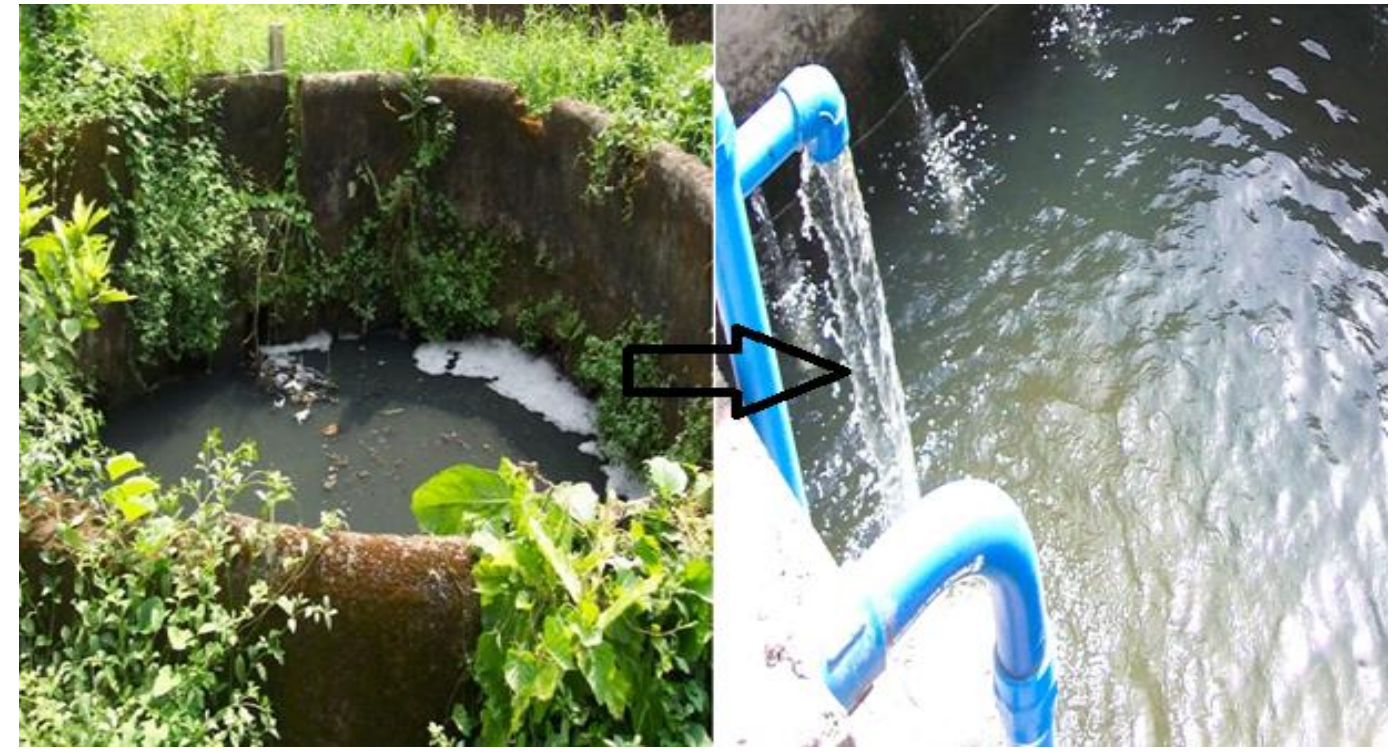

Figure 1- Change in Water quality after treatment from an SBT plant

\subsection{LAYOUT OF A SOIL BIOTECHNOLOGY SET-UP}

Comprising of several innovative features, an SBT plant has got a very simple set up. The untreated water is first stored in a tank, which is later pumped into the bio-reactor and after treatment it is collected in the fresh water tank under the flow of gravity.

The tanks can be underground or overhead and can be made out of brick, steel or concrete depending upon the feasibility.

The bioreactor contains material having almost the similar density as that of the soil in its surrounding. Hence if no load bearing structures are required if the bioreactor in constructed inside the ground. The design of a bioreactor can be mould for special requirements.

Figure 2 shows, there are no moving parts in the bioreactor hence the energy consumption is very low. There is one pump to pump the raw water onto the reactor and one to pump the treated at the site of use. The reactor is composed of graded material starting from big gravels at the bottom. Over this, a thick layer of media is placed which comprises of the biomass. This whole set up is covered with a thin layer of soil in which some shrubs can be planted giving a look of a garden as shown in the figure 3.

The whole set up is completely odourless and eco-friendly. There is no unwanted sound produced during its operation.

Hence an SBT could be easily installed in a house, a society or anywhere in a city without any area constraints or facing any restrictions from the people living in its vicinity. 
Civil Engineering and Urban Planning: An International Journal(CiVEJ) Vol.2,No.4, September 2015

\subsection{FEATURES OF SOIL BIOTECHNOLOGY}

\section{(a) Higher Efficiency}

One of the most fundamental parameters of a water treatment plant is the F/M ratio. F/M ratio in simple words is the ratio of the dirty unwanted matter present in the untreated water to the number of microbes available in the medium in which the water is being treated. Broadly, there are two classes of media to treat water, one is aquatic treatment and the other is terrestrial treatment.

The microbial diversity in water is $10^{7}$ to $10^{8}$ cells/g whereas in soil it is almost double, $10^{12}$ to $10^{16}$ cells/ g. The BOD load entering the plant is the food for the biomass present in the reactor. Hence due to higher microbial diversity in soil, a treatment technology based in soil will be more efficient than the one based in water with a lesser F/M ratio. Being a terrestrial technology, SBT can efficiently treat waste water giving results better than any conventional aquatic technology such as ASP, MBR etc. that too in a minimal operational cost.

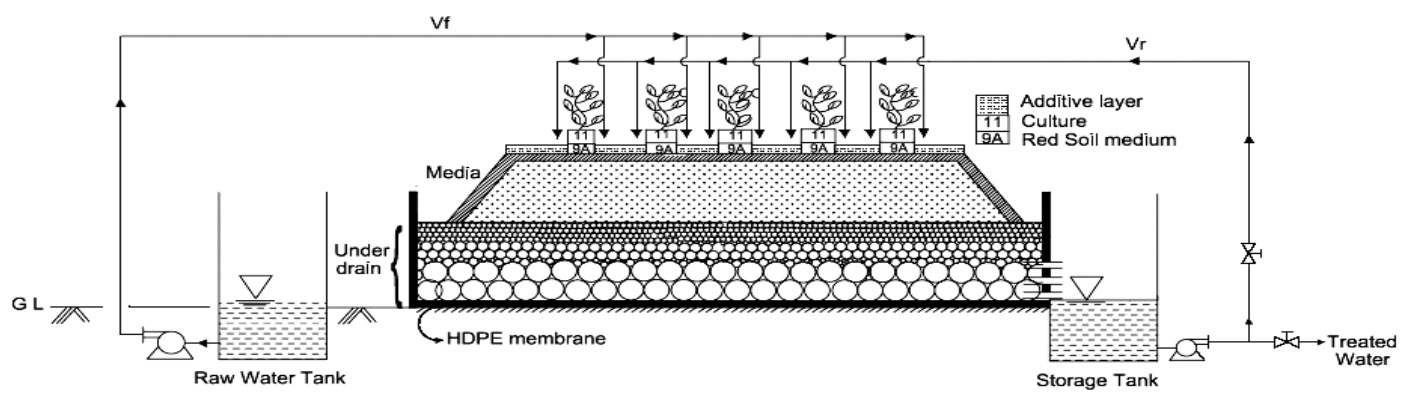

Figure 2- Sectional view of an SBT set up

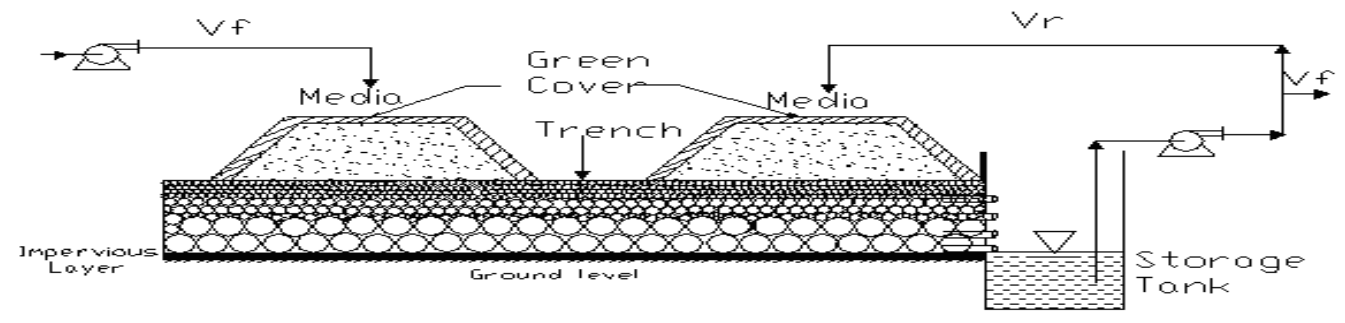

Figure 3- Layout for processing of wastewater

\section{(b) No requirement of Mechanical Aeration}

Another unique feature of SBT is that there is no need of providing mechanical aeration unlike ASP or other technologies. The purpose of injecting oxygen is to facilitate the process of degradation of organic matter during treatment of waste water. Another function of aeration is to agitate the water to let the biomass come in direct contact with the suspended matter. The problem with this aeration process is that it consumes a large amount of electrical energy and it has to be maintained for prolonged hours. Also, air contains only 21 percent of oxygen, and the rest of air containing nitrogen goes for waste. If the aeration process is not done properly then it results in poor water quality. 
In case of SBT, the aeration is eliminated by natural processes. The fundamental actions of nature; namely respiration, photosynthesis and mineral weathering are brought together in a common media containing selected set of microorganisms. The combination is such made that there is no need of introducing oxygen from outside.

\section{(c) No Sludge Generation}

A major concern with the operation of other technologies is the sludge or back wash water disposal. For example, in the case of ASP, large amount of sludge gets collected in the settling tank which is to be removed and disposed of on a regular basis other it would affect the water quality. The sludge is discharged into nearby drains which eventually pollute some other water resource, as in Sikandara water treatment plant, Agra, where sludge is discharged into river Yamuna. Another way to manage sludge generation is to sludge drying. In this the sludge is spread over large area and is allowed to dry till it gets converted into a fertilizer or manure. This sometimes may be hazardous as some contaminants may pollute the land or the ground water. It also generates a foul smell and occupies large area.

This calls for another beneficial feature SBT i.e. its ability to prevent sludge generation. As the intense population of microbes in soil manages the entire BOD load of the plant and doesn't lead to the formation of any by-product or gases like hydrogen sulphide, ammonia, carbon Disulphide etc. which cause odour in the vicinity of the plant. Hence no area or efforts are required to handle sludge.

In fact an added advantage of this technology is that the top soil layers if replaced timely proves to be a green manure and can be used for agriculture purposes.

\section{METHODOLOGY}

The efficiency of an SBT plant for the removal of BOD, COD, TSS and TDS studied previously and reported by the authors [1]. The soil biotechnology based treatment plant of Sourav Pharmaceuticals; Chandigarh a sewage treatment plant at Luckhnow Airport was studied. The influent and effluent samples were collected from the plants and tested for the above mentioned parameters. The efficiency of the SBT was determined and comparison of it with the existing STP and CETP of Gurgaon and Delhi were made.

Further it has to be analysed that, if the Nazafgarh drain water carrying several characteristic parameters is treated in an SBT plant then what would be the effluent characteristics. Taking the efficiency consideration of the existing plants, the percentage removal of the various parameters of the Nazafgarh drain has been done. These have been recorded in the table 1 . The effluent parameters are in accordance with IS2490 (Part I)-1974 which gives tolerance limits for industrial effluents discharged into inland surface water.

Table 1- Characteristics of Nazafgarh Drain water before and after treatment through SBT

\begin{tabular}{|c|c|c|c|}
\hline & Influent & \%age removal & Effluent \\
\hline BOD $(\mathrm{mg} / \mathrm{L})$ & 260 & 91.6 & 21.84 \\
\hline COD $(\mathrm{mg} / \mathrm{L})$ & 7500 & 91.5 & 637.50 \\
\hline TSS $(\mathrm{mg} / \mathrm{L})$ & 476 & 89.76 & 48.74 \\
\hline TDS $(\mathrm{mg} / \mathrm{L})$ & 4800 & 20.83 & 3800.16 \\
\hline
\end{tabular}


Civil Engineering and Urban Planning: An International Journal(CiVEJ) Vol.2,No.4, September 2015

It is suggested to go with the SBT plant with capacity 1 MLD. Later the design aspects of a 1MLD SBT plant was taken into account which if set up near the river Yamuna, where the water coming from Nazafgarh drain area would first be treated and then disposed into the river. The treated water quality will be appreciated to prevent the pollution of the river.

The area required to install a 1 MLD SBT plant is around $1500 \mathrm{sqm}$ as per the convention rule of area requirement i.e. $1.5 \mathrm{sqm}$ for every $1 \mathrm{KLD}$. Further the depth required for the bioreactor is $2.5 \mathrm{~m}$. The capacity of the inlet storage tank needs to be at least $60 \%$ and for the treated water, it's around $40 \%$ of the total plant capacity.

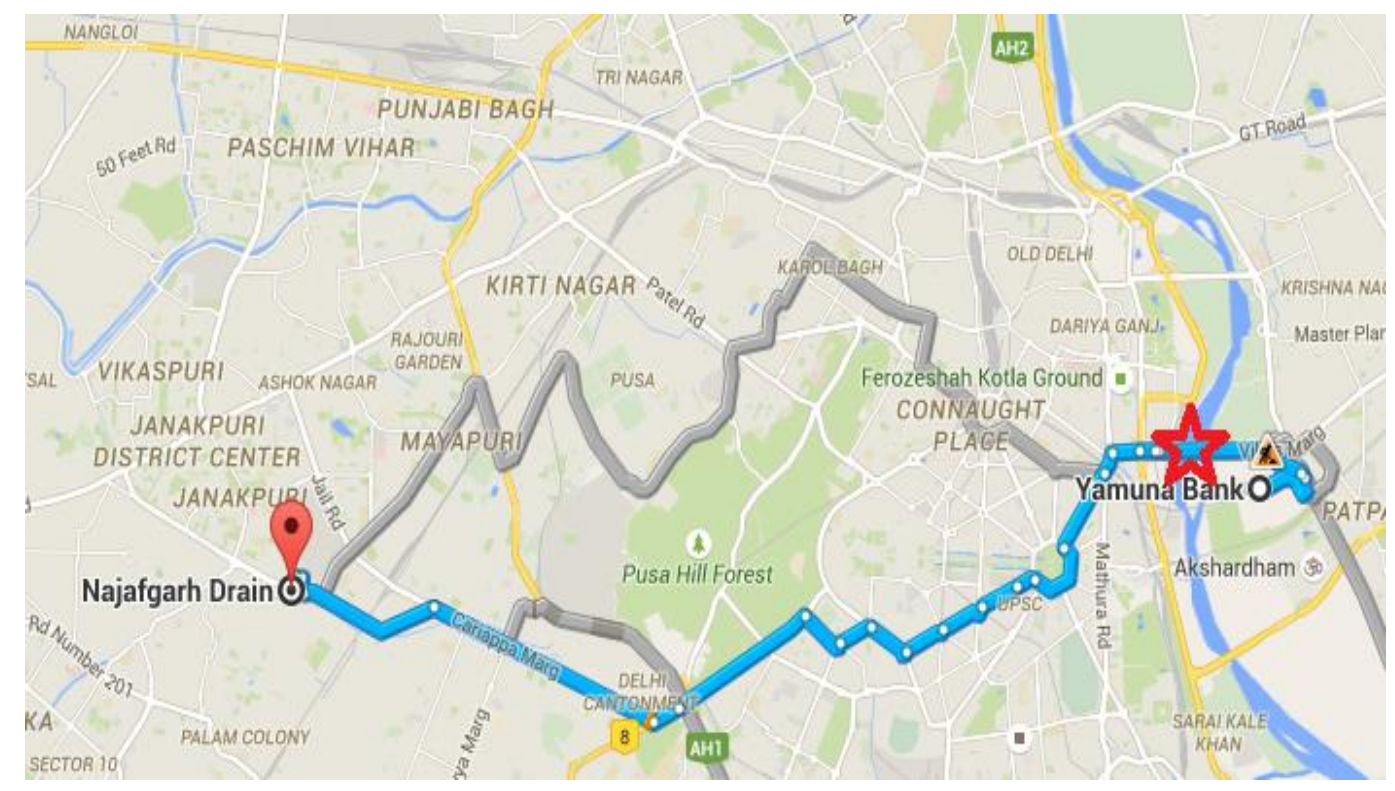

Figure-4 Suggested location for a water treatment plant

The star pointer shows the area of interception of Nazafgarh Drain and river Yamuna. An area around this is the most suitable area to establish a water treatment plant, which can dispose its effluent into the river without polluting it.

\section{CONCLUSION}

Soil Biotechnology not only treats water for disposal but recycles it to the standards that it can be reused. Almost 50\% of water consumption is for purposed like flushing, horticulture, cleaning, washing etc. which can be served by the recycled water from an SBT plant.

On the other hand, setting up an SBT plant to treat the Nazafgarh Drain water would help to prevent the deterioration of river Yamuna to a great extent. Since the applied technology is not demanding i.e. no skilled labour or high operational and maintainance cost is needed hence it would sustain easily in the adverse conditions without any breakdown.

It's a high time to realise that the Nazafgarh drain was also a river earlier by the name of Sahibi, which is now a major contributor to the pollution of the only water resource of the Capital. Hence this innovative soil biotechnology would prove to be a boom in the field of water treatment and a great step towards a better tomorrow. 
Civil Engineering and Urban Planning: An International Journal(CiVEJ) Vol.2,No.4, September 2015

\section{ACKNOWLWGDMENTS}

A sincere gratitude and thanks to Dr. Avinash Kadam (Ph.D, IIT Bombay) for providing some the essential data and help throughout the work. The officials of Sugam Paryavaran Vikalp Pvt Ltd have been a great support.

\section{REFERENCES}

[1] Rupali Gupta, Shivam Aggarwal and Vaibhaw Vishal, Comparison of conventional water treatment technologies with soil biotechnology. International Journal of Advanced Technology in Engineering and Science (ISSN 2348-7550).

[2] M. von Sperling, V.H. Freire and C.A. de Lemos Chernicharo, Performance evaluation of a UASB activated sludge system treating municipal wastewater, Water Science and Technology Vol 43 No 11 pp 323-328 (C) 2001 IWA Publishing and the authors

[3] Charles J. Moretti, Dipesh Das, Brian T. Kistner , Harvey Gullicks and Yung-Tse Hung, Activated Sludge and Other Aerobic Suspended Culture Processes, Water 2011, 3, 806-818; doi:10.3390/w3030806

[4] S.K.GARG- Water supply and sanitary engineering, Khanna publishers, Delhi.

[5] Report on "STATUS OF WATER TREATMENT PLANTS IN INDIA", CENTRAL POLLUTION CONTROL BOARD. (www.cpcb.nic.in) 